\title{
The correlation of carotid plaque pathohistologic features and neurological symptoms: A meta-analysis of observational studies
}

\author{
Peng Gao, Zuo-quan Chen, Li-qun Jiao*, Feng Ling \\ Department of Neurosurgery, Tongji Hospital, Tongji University, 389 XinCun Road, Shanghai - 200065, and *Department of \\ Neurosurgery, Xuanwu Hospital, Capital University of Medical Science, Beijing - 100053, China
}

\begin{abstract}
Objective: To investigate the association between the pathological features of carotid plaque and ipsilateral symptoms of cerebral ischemia. Materials and Methods: We sought to identify clinical observational studies comparing the incidence of pathological features between symptomatic and asymptomatic carotid plaques in terms of ulceration, thrombosis and intraplaque hemorrhage (IPH), published between 1996 and 2006. A search on, PubMed was supplemented by a review of bibliographies of relevant articles and lists of references in it. Odds ratios (OR) for the presence of each feature as a role in the pathogenesis of neurological events were calculated and combined by a meta-analysis. Results: We integrated 16 clinical studies totaling 2839 plaques harvested at endarterectomy procedures. The reported incidence for each feature was highly variable. The methods in defining ulceration, thrombosis and IPH were very heterogeneous. The time intervals between the latest onset of ischemic symptoms and pathological examinations varied greatly. Overall, the incidence of ulcerated plaques in the symptomatic group were significantly higher than that in the asymptomatic group (study number, $n=10$; OR, 2.32; $95 \% \mathrm{Cl}, 1.90-2.83$. A random-effect model was performed among studies regarding surface thrombosis because an apparent trend for heterogeneity was observed ( $n=6$; OR, $1.57 ; 95 \% \mathrm{Cl}, 0.68-3.64)$. There was no difference with respect to IPH between the two groups ( $n=11$; OR, 1.09; $95 \% \mathrm{Cl}, 0.91-1.32)$. Conclusions: Ulcerated carotid plaque is significantly correlated with the production of neurological events, whereas thrombosis fails to correlate with ischemic symptoms because of the presence of substantial heterogeneity. The association between IPH and clinical presentations is less clear.
\end{abstract}

Key words: Asymptomatic carotid stenosis, endarterectomy, symptomatic carotid stenosis, pathology, meta-analysis
The current meta-analysis provided comparative information with regard to the incidence of ulceration, thrombosis, and intraplaque hemorrhage between symptomatic and asymptomatic plaques. A significant relationship was established between the manifestations of cerebral ischemia and ulceration, whereas thrombosis failed to correlate with ipsilateral symptoms of cerebral ischemia because of the presence of substantial heterogeneity across studies. The correlation between intraplaque hemorrhage (IPH) and neurological events is less clear. It should be noted that the reported incidence for each feature was highly variable. The methods in defining ulceration, thrombosis, and IPH were very heterogeneous. The time intervals between the latest onset of ischemic symptoms and pathological examinations varied greatly. More considerations should be given to the uniformity in definition as well as the control of confounders and time intervals in future studies.

In the past decades, several multi-center randomized control trials ${ }^{[1-3]}$ have demonstrated the superiority of carotid endarterectomy (CEA) compared with the best medical treatment for the prevention of stroke for both symptomatic and asymptomatic patients with carotid artery disease. The decision of whether to perform CEA should be made on the basis of data including degree of stenosis and pathological characteristics of the carotid lesion, as well as issues of medical and surgical morbidity $(<3 \%)$.

Recently, more attention has been focused on carotid plaque pathology. A number of studies have shown that, in association with the degree of carotid stenosis, pathological features, such as ulceration, thrombosis and IPH, could also be important in determining whether an ICA lesion remains clinically silent or becomes symptomatic. ${ }^{[4-5]}$ Therefore, better insight into which pathological features lead to subsequent symptoms will provide the surgeon with the opportunity to operate 
selectively those who are at great risk.

Nevertheless, the causal relationship of pathological features (particularly for surface thrombus and IPH) to a history of ipsilateral brain ischemia before CEA was reported conflicting. Conclusive data by means of a quantitative synthesis were also not available.

This systematic review was designed to utilize quantitative methods for combining information across different studies over a span of 11 years. It was undertaken to determine whether a correlation could be established between pathological features of carotid plaque and clinical presentations. Also, the effect sizes were estimated and possible sources of heterogeneity in results across studies were identified and explained.

\section{Materials and Methods}

\section{Search strategy}

We sought observational studies in English, published between January 1996 and September 2006, inclusive. (1) We identified studies by comprehensive text-words and MeSH-based electronic searches of Medline (Entrez PubMed NIH); (2) Electronic search terms included: carotid stenosis/plaque, pathology, histology, ulcerated or ulceration, thrombosis or thrombus, Intra-plaque hemorrhage or intramural hemorrhage; (3) The abstract of each article was carefully reviewed to detect appropriate publication; (4) Perusal of all reference lists of all relevant articles containing data that concerned were checked for further leads; (5) Additionally, we did a manual search of the following journals: Stroke and Journal of Vascular Surgery.

\section{Inclusion criteria}

Studies were included if: (1) specimens were harvested at endarterectomy and the pathological features were characterized; (2) they compared the incidence of pathological features between symptomatic and asymptomatic patients; (3) basic data regarding the frequency of ulceration, thrombosis and IPH were provided in both groups.

Generally, there were two methods used for defining: microscopic (histological) examination and macroscopic (gross) inspection. Specimens should be removed en bloc in order to avoid misleading gross findings. Histological features were evaluated by examining sections. Patients or plaques were defined as symptomatic if ipsilateral symptoms of cerebral ischemia were present within the last six months, such as transient ischemic attack (TIA), amaurosis fugax (AFX) or stroke. Asymptomatic plaques were from patients without symptoms or from the side without symptoms in those undergoing bilateral operations.

\section{Exclusion criteria}

Studies that met one of the following items were excluded: (1) animal studies, case reports, editorials, letters and reviews; (2) highly selected studies (symptomatic patients only); (3) failed to characterize the pathological features; (4) nonatherosclerotic carotid stenosis (e.g., fibromuscular dysplasia, postradiotherapy); (5) restenosis reports (e.g., occurring after endarterectomy or carotid angioplasty and stenting). Multiple publications from the same project were eliminated from the meta-analysis and the one that was most appropriate to this review was recruited.

\section{Data extraction}

The following general descriptive information was extracted from each study: (1) number, age and sex of participants; plaque number; (2) time intervals between the latest onset of ischemic symptoms and pathological examinations; (3) methods of evaluation: macroscopy or microscopy; (4) numbers of plaques with ulceration, thrombosis and IPH assigned to each group; (5) risk factors for atherosclerosis.

The authors (P. G, F. L and Z. Q. C.) selected the studies to be included in the review, extracted the data independently and cross-checked them, with disagreement resolved by consensus.

\section{Statistical analysis}

We calculated the odds ratio (OR) in each study. The statistical validity of aggregating the studies was assessed with a $\chi^{2}$ for heterogeneity by means of a standard fixedeffect model of overview $(P<0.1$ suggests that the assumption of homogeneity was violated). A random-effect model was performed if an apparent trend for heterogeneity was observed. If the value of OR was more than 1 , the risk of a particular feature was greater within symptomatic groups.

We performed sensitivity analysis to test the results under varied conditions such as the exclusion of studies that contributed the largest number of plaques and as a group. The meta-analysis was performed using RevMan (Version 4.2.8). Potential publication bias was assessed using an inverted funnel plot for asymmetry. Egger's and Begg's methods were used to test publication bias objectively (Version 9.0, STATA). A cut-off $P$ value of 0.1 was used as the positive threshold bias to assess the power of statistical test.

\section{Results}

Thirty-six potentially relevant studies were identified. We excluded seven that were validation studies comparing carotid plaque imaging with histology; ${ }^{[6-12]}$ five that failed to provide sufficient data in each group; ${ }^{[13-17]}$ five that were highly selected studies; ${ }^{[18-22]}$ three studies in which ulcerated plaques were identified by angiography in vivo. ${ }^{[23-25]}$

The remaining 16 studies included 2769 patients totaling 2839 carotid plaques [Table 1]. The ratio of males to 
Table 1: Summary of 16 clinical studies

\begin{tabular}{|c|c|c|c|c|c|c|c|c|c|c|}
\hline \multirow[t]{2}{*}{ References } & \multirow[t]{2}{*}{ Year } & \multirow[t]{2}{*}{ Micro $\ddagger$} & \multirow[t]{2}{*}{ Macro§ } & \multirow[t]{2}{*}{ Case no. } & \multirow[t]{2}{*}{ Plaque no. } & \multicolumn{2}{|c|}{ Symptoms } & \multicolumn{3}{|c|}{ Pathological features } \\
\hline & & & & & & + & - & Ulceration & Thrombus & $\mathrm{IPH}^{\star \star}$ \\
\hline Carr ${ }^{[26]}$ & 1996 & + & + & 44 & 44 & 19 & 25 & 4 & 32 & 30 \\
\hline Bassiouny ${ }^{[27]}$ & 1997 & + & + & 99 & 99 & 59 & 40 & 27 & 7 & 18 \\
\hline Park $^{[28]}$ & 1998 & $\ldots$ & + & 1008 & 1008 & 623 & 385 & 713 & $\mathrm{ND}^{4}$ & 299 \\
\hline McCarthy ${ }^{[29]}$ & 1999 & + & $\ldots$ & 28 & 28 & 13 & 15 & 11 & ND & 11 \\
\hline Montauban ${ }^{[30]}$ & 1999 & + & $\ldots$ & 47 & 47 & 33 & 14 & ND & ND & 41 \\
\hline Ballotta $^{[31]}$ & 2000 & $\ldots$ & + & 401 & 457 & 289 & 168 & 338 & $\mathrm{ND}^{4}$ & 155 \\
\hline $\mathrm{Kim}^{[32]}$ & 2000 & + & + & 55 & 55 & 38 & 17 & 49 & ND & ND \\
\hline Tegos $^{[33]}$ & 2000 & + & $\ldots$ & 67 & 71 & 46 & 25 & ND & ND & 50 \\
\hline Mallat ${ }^{[34]}$ & 2001 & $\ldots$ & + & 22 & 22 & 13 & 9 & 15 & ND & ND \\
\hline Stork ${ }^{[35]}$ & 2002 & $\ldots$ & + & 109 & 109 & 71 & 38 & 68 & 23 & 82 \\
\hline Milei[i36] $^{36}$ & 2003 & + & $\ldots$ & 272 & 281 & 133 & 148 & ND & 32 & 74 \\
\hline Spagnoli ${ }^{[37]}$ & 2004 & + & $\ldots$ & 269 & 269 & 187 & 82 & ND & 115 & ND \\
\hline Fisher ${ }^{[38]}$ & 2005 & + & $\ldots$ & 208 & 208 & 80 & 128 & 45 & 42 & ND \\
\hline Tziakas $^{[39]}$ & 2005 & $\ldots$ & + & 18 & 19 & 11 & 8 & ND & ND & 7 \\
\hline Krupinski[40] & 2006 & + & + & 38 & 38 & 29 & 9 & 26 & ND & ND \\
\hline Turu ${ }^{[41]}$ & 2006 & + & + & 84 & 84 & 55 & 29 & ND & ND & 38 \\
\hline
\end{tabular}

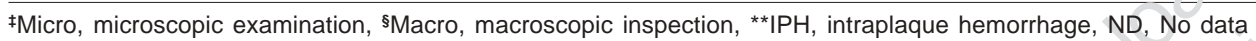

females was 2.2:1. The average age was 68.5 years. The number of carotid plaques in the studies ranged from 19 to 1008 (median, 78). There were 1699 symptomatic plaques and 1140 asymptomatic plaques (ratio, 1.5:1) altogether. Associated risk factors were equally distributed in eight studies ${ }^{[26,27,29,34,36,37,40,41]}$ and were not stated in the remaining. Five studies harvested plaques from groups with equal severity of carotid stenosis. ${ }^{[26,27,29,33,37]}$ The presenting symptoms were further sub-typed into transient symptoms and prior stroke in six studies. ${ }^{[28,31,33,37,38,41]}$ The time intervals between the latest onset of symptoms and surgery were available from 13 studies, ${ }^{[26-31,33-39]}$ with great variations. Plaque specimens were evaluated in five studies by macroscopy ${ }^{[28,31,34,35,39]}$ and in 11 by microscopy or a combination of both. For macroscopy, the basis for evaluation was in situ observation and photography after arteriotomy ${ }^{[28,31]} \mathrm{We}$, along with Lovett's review, ${ }^{[42]}$ found that histological methods including position, number, stains and frequency of section varied considerably. A transversal microscopic evaluation was performed among all the included studies.

There were three studies specifying the details about the interference of severity of stenosis with plaque morphology. ${ }^{[28,31,38]}$ They all found that the frequency of plaque ulceration was independent of the degree of ICA stenosis. As for IPH, Park et al indicated that hemorrhage occurred more frequently in the highly stenotic lesions. ${ }^{[28]}$ In Ballotta's study, the frequency of IPH also appeared increased with the extent of disease, but the difference did not reach significance. ${ }^{[31]}$ The presence of thrombus was unaffected by the degree of stenosis in Fisher's study. ${ }^{[38]}$

\section{Ulceration}

Among 10 studies, ${ }^{[26-29,31,32,34,35,38,40]}$ a significantly higher incidence of ulceration was found in the symptomatic group compared with asymptomatic [Figure 1A]. Because the two largest studies that contributed approximately $70.8 \%$ of the total number of plaques dominated the results of the overview, ${ }^{[28,31]}$ we performed a meta-analysis (exclusion of the two studies) to test the robustness of the result. The strength of association was even stronger and the sensitivity analysis did not substantially alter the point estimates of the results. No visual asymmetry could be observed in Funnel plotting [Figure 1B]. Formal statistical testing did not indicate evidence of publication bias

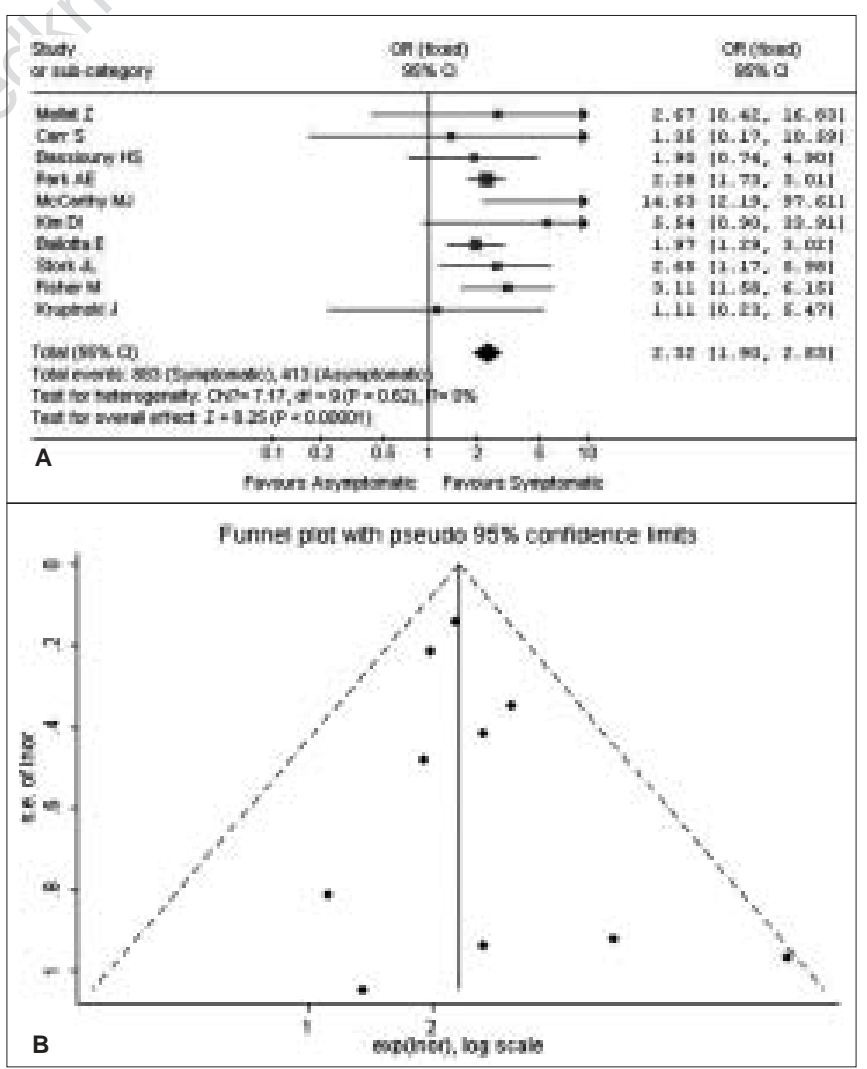

Figure 1: A. Pooled estimate of ORs and $95 \% \mathrm{Cl}$ for ulcerated carotid plaques (via a fixed-effect model). B. Assessment of publication bias using the funnel plot. No asymmetry was observed 
$(P=0.398,0.655$ for Egger's and Begg's test, respectively).

\section{Surface thrombosis}

Six studies ${ }^{[26,27,35-38]}$ were identified focusing on the characterization of surface thrombosis. The reported incidence had been highly variable (7.1-72.7\%, median $20.7 \%$ ). Thrombosis was defined diversely. Microscopically, Spagnoli et al defined a thrombotically active plaque as the presence of an acute thrombus constituted of platelet or fibrin on the plaque surface. In this context, thrombosis was divided into two categories: thrombus associated with plaque rupture and super-facial erosion. ${ }^{[37]}$ The former category, rather than erosion, was significantly correlated with the presence of ischemic symptoms. Fisher et al stressed that the criteria for the presence of thrombosis required a substantial-sized lesion. In this study, thrombus was considered present only when the lumen surface was covered by thrombotic material larger than $340 \times 110 \mu \mathrm{m} \cdot{ }^{[38]}$ Macroscopically, thrombus was defined as that adherent to the plaque surface and/or propagating into the arterial lumen. ${ }^{[35]}$ Of note, two studies indicated that fresh specimens were rinsed to remove surface blood. ${ }^{[27,36]}$ No definitions were specified in one study. ${ }^{[27]}$ We began with a fixed-effect model for our analysis. The magnitudes of overall differences between two groups were of statistical significance [Figure 2A]. However, homogeneity test indicated an extreme trend for heterogeneity among studies. Estimated effect sizes were then combined via a random-effect model and the differences between the two groups lost significance [Figure 2B].

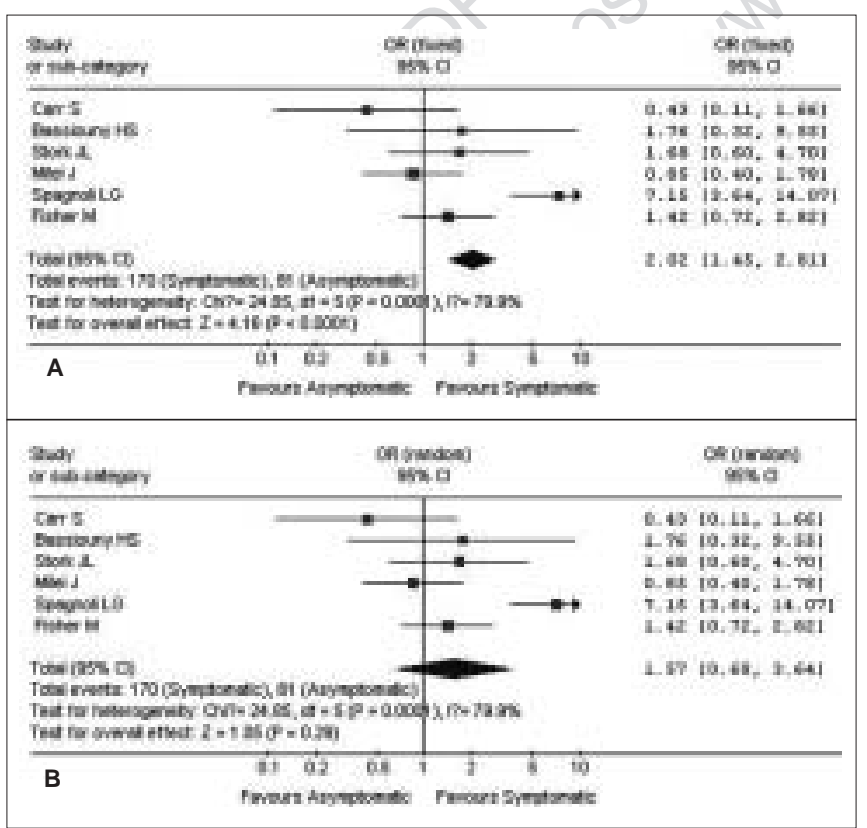

Figure 2: A. Pooled estimate of ORs and $95 \% \mathrm{Cl}$ for surface thrombosis of carotid plaque (via a fixed-effect model).

B. Pooled estimate of ORs and $95 \% \mathrm{Cl}$ for surface thrombosis of carotid plaque (via a random-effect model)

\section{Intraplaque hemorrhage}

Pathologic evaluation was investigated in four studies $^{[28,31,35,39]}$ by macroscopy and in seven ${ }^{[26,27,29,30,33,36,41]}$ by microscopy. The incidence of IPH had been reported highly variable (18.2-87.2\%, median 39.3\%). The methods in defining IPH ranged remarkably, from visual inspection of gross sections, ${ }^{[28,31]}$ microscopic evidence of red blood cells, ${ }^{[26,29,39]}$ histological evidence of hemosiderins, ${ }^{[33,36]}$ to a combination of all degenerated blood constituents. ${ }^{[26]}$ For macroscopy, IPH was usually characterized by its immediate recognition or on transecting the plaques at the time of arteriotomy. ${ }^{[26,28,31]}$ Studies in which light microscopy was performed, had been based on a broad definition of hemorrhage. Definitions were not specified in three studies. ${ }^{[27,30,41]}$ The magnitudes of overall difference between two groups failed to yield statistical significance. Likewise, insignificant differences were reproduced in sub-group analyses with respect to macroscopy and microscopy [Figure 3].

All the results are summarized in Table 2.

\section{Discussion}

\section{Ulceration}

The first result of this review is the demonstration of a strong association between plaque ulceration and an initial presentation with TIA, AFX or stroke. As early as the 1970s, a strong association was found between plaque ulceration and clinical presentations. ${ }^{[43-44]}$ This correlation was reproduced in subsequent studies ${ }^{[28,31,45,47]}$ except two. ${ }^{[26,46]}$ It was further verified in our meta-analysis.

It should be noted that the reported incidence has been highly variable in the literature (9.1-89.1\%, median $65.3 \%$ ), partly explained by the diverse methods in defining. Pathologically, such ulcers have been previously defined as plaque surface defects of at least $1 \mathrm{~mm}$ or more than $560 \mu \mathrm{m}$ in diameter and depth. ${ }^{[48-50]}$ Usually, gross ulceration was considered as plaque surface irregularity

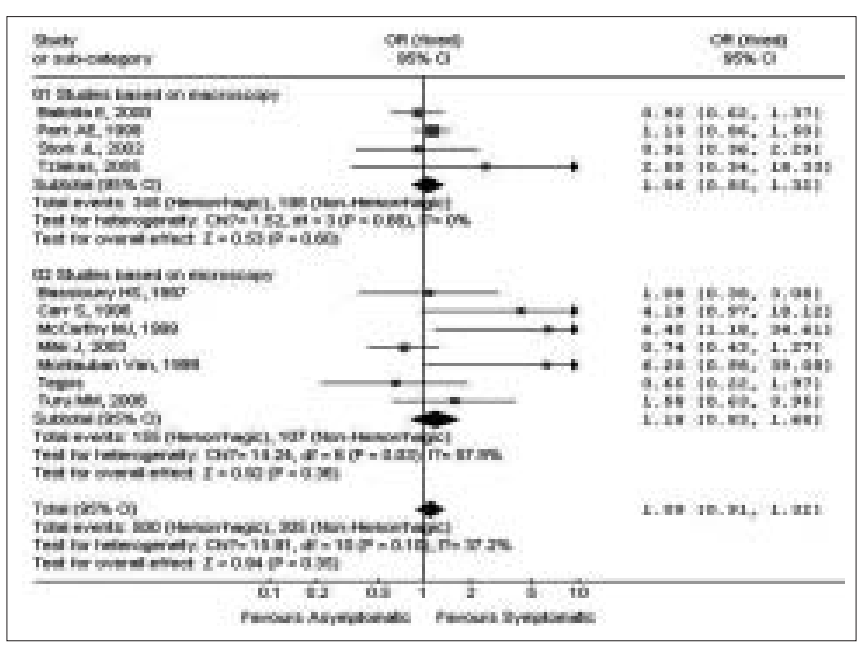

Figure 3: Pooled estimate of ORs and $95 \% \mathrm{Cl}$ for intraplaque hemorrhage (via a fix-effect model) 
Table 2: Summary of pooled odd ratios and $95 \%$ confidence interval

\begin{tabular}{lccccc}
\hline Types of studies combined & $\mathbf{N}$ & Odd ratios & $95 \%$ confidence interval & $\boldsymbol{P}$ value & Test for heterogeneity \\
Ulceration & 10 & $2.32^{\mathrm{a}}$ & $1.90-2.83$ & $<0.00001$ & 0.62 \\
Thrombosis & 6 & $2.02^{\mathrm{a}}$ & $1.45-2.81$ & 0.0001 & 0.0001 \\
Thrombosis & 6 & $1.57^{\mathrm{b}}$ & $0.68-3.64$ & 0.0001 & 0.10 \\
Intraplaque hemorrhage & 11 & $1.09^{\mathrm{a}}$ & $0.91-1.32$ & 0.36 & 0.03 \\
microscopic studies & 7 & $1.18^{\mathrm{a}}$ & $0.83-1.68$ & 0.60 & 0.68 \\
macroscopic studies & 4 & $1.06^{\mathrm{a}}$ & $0.85-1.32$ &
\end{tabular}

${ }^{a}$ Values were calculated with a fixed-effect model, ${ }^{b}$ Values were calculated with a random-effect model.

at the time of arteriotomy. Pinholes of less than $1 \mathrm{~mm}$ or smooth invaginations with no evidence of disruption of fibrous cap were not considered. ${ }^{[28,31]}$ In contrast, the definitions of microscopic ulceration tended to be more variable. In Carr's study, plaques with evidence of rupture were classified separately from those with intimal disruption without rupture. Thus few plaques were identified with microscopic ulceration and no significant difference was found between two groups. ${ }^{[26]}$ Fisher et al described a relatively low incidence $(21.6 \%)$ compared with other studies, because the presence of histological ulceration required a substantial size (560 $\mu \mathrm{m}$ or more). ${ }^{\left[{ }^{[3]}\right]}$ Currently, the correlation between ulceration and degree of stenosis remains a controversial matter. ${ }^{[28,31,38,45]}$ There has been no evidence that the pathogenetic role of ulceration might differ between patients with transient ischemia and those with prior stroke.

\section{Thrombosis}

Thrombosis, frequently secondary to disruption of carotid plaques, appears to be important for the production of ischemic symptoms. A large clinicopathologic series of CEA specimens has demonstrated that thrombosis associated with plaque rupture was one of the major determinants of ischemic stroke. ${ }^{[37]}$ Further evidence could be found that luminal thrombosis was the main source of downstream cerebral microemboli as detected by transcranial Doppler monitoring. ${ }^{[51]}$ Unfortunately, we observed an extreme tendency for heterogeneity across studies. An insignificant estimator was observed by combing effects via a random-effect model.

The occurrence of major heterogeneity across studies was partly due to the lack of consensus and consistency in defining surface thrombosis. Differences in the identification of thrombus could account for variable pathogenetic role in the symptom production. Thrombosis could be defined either visually or microscopically. Gross assessment was usually susceptible to subjective judgment. Some misleading findings may also be introduced by rinsing to remove surface blood. Thus, it otherwise explained the fact that reported incidence of thrombus varied widely from one to another. Second, some ${ }^{[37,38,52]}$ noted that the low incidence of thrombus was associated with a longer time interval between the onset of symptoms and pathological examination. Symptomatic carotid stenosis is usually defined by the occurrence of neurological symptoms related to the side of stenosis within the last six months prior surgery. However, Spagnoli et al even included some patients with a time interval of 30 months. ${ }^{[37]}$ Variable time intervals appeared to account for some of the heterogeneity. Finally, factors such as long-term preoperative administration of aspirin and use of heparin during surgery could modulate the development of thrombosis as well. ${ }^{[36]}$

On the other hand, there was some evidence that thrombosis was less important in the production of symptoms. It was found that the presence of thrombosis was strongly associated with ulceration and IPH. ${ }^{[21,38]}$ Ulceration represents an important substrate from which thrombus may later arise. Thrombus hence sometimes failed to serve as a separate entity per se. This could potentially prevent it from being an independent risk factor for neurological events.

Additionally, there were two studies in which symptoms were sub-typed into transient ischemia and prior stroke. Fisher et al found that thrombus was similarly observed between TIA and stroke groups, ${ }^{[38]}$ whereas in Spagnoli's report, the incidence of thrombosis in major stroke group was significantly higher than that in TIA group $(P<0.001) .{ }^{[37]}$ The pathogenetic role of thrombus appeared varying over the types of ischemic symptoms. It suggested neurological symptoms should be stratified in future studies instead of a simple combination of AFX, TIA or stroke or the findings might be overinterpreted.

\section{$I P H$}

There has been considerable emphasis on the role of IPH in the pathogenesis of brain ischemia following extensive clinico-pathologic analysis. Unfortunately, previous studies presented a mass of conflicting results. ${ }^{[46,47,53-56]}$ Our meta-analysis suggested a null correlation. Sub-category analysis in terms of the methods of definition was performed and an insignificant correlation was observed in each group.

Effect might be invalidated by the heterogeneous methods of definitions. Tiny or small hemorrhage may be overlooked grossly. Microscopy tended to be more sensitive for detecting IPH than macroscopy. ${ }^{[26]}$ Diverse histological methods of definition could be found across studies as well. Therefore, a uniform and accurate method for definitions is necessary. Second, insignificant effect 
could be partly explained by the variable intervals between the latest onset of ischemia and pathological examinations. Lusby et $a^{\left[{ }^{[54]}\right.}$ suggested a short interval (2.9 weeks) as a key factor in establishing the positive correlation between acute hemorrhages and clinical manifestations. However, our review included studies with intervals ranging from within several weeks ${ }^{[26,30]}$ to six months. ${ }^{[27,36]}$ Acute or fresh IPH could be stabilized by a process of healing or turning into an avascular structure (calcified or fibrous tissues) as time goes by. Therefore, the true number of IPH could be underestimated in symptomatic groups. Finally, as previous studies suggested that IPH occurred more frequently with high-grade stenosis, ${ }^{[28,57,58]}$ carotid artery severity, this confounder that was related to both the presence of IPH and the neurological symptoms under study, could potentially distort results. To correct for the confounder, it is recommended that equal severity in both groups should be assumed in the subsequent studies. However, details were specified in only four studies out of 11. . $^{[26,27,29,33]}$

Likewise, there was some evidence that the pathogenetic role of IPH might differ between patients with transient events and those with permanent neurological deficits. ${ }^{[28,31]}$ Basic data were provided in only four studies..$^{[28,31,33,41]} \mathrm{A}$ summation calculation for them suggested the incidence of IPH was not significantly different between asymptomatic and transiently symptomatic groups (32.5\% vs. $31.2 \%, P=0.632$ ). Nevertheless, there was a salient trend of more IPH in the prior stroke group, compared with asymptomatic group ( $43.8 \%$ vs. $32.5 \%$; $P=0.003)$.

Currently, improved technology and resolution have resulted in the capacity to quantify plaque components. ${ }^{[59,60]}$ Pixel analysis at ultrasonography and local temperature probes as well as ${ }^{111}$ Indium-platelet scintigraphy is able to help in identifying vulnerable plaques. ${ }^{[61-63]}$ Also, high-resolution MRI could not only identify, but also stage intraplaque hemorrhage with good accuracy and reproducibility in advanced atherosclerotic carotid plaques. ${ }^{[12]}$ Therefore, a better understanding of its role in plaque stability and evolution would be achieved. ${ }^{[64]}$ Moreover, current techniques provide an opportunity to prospectively examine the relationship between plaque features and subsequent cerebrovascular events. ${ }^{[8]}$ Early interventions aimed to prevent imminent neurological events might be more justifiable.

Generally, there were three methodological issues that could influence the strength of association including diverse methods of definitions, variable time interval and the unequal degree of carotid stenosis. One limitation of this meta-analysis may be the heterogeneity of the different studies as far as the populations studied were concerned. Statistical validity of our meta-analysis could be potentially attenuated by the variation in the criteria used in defining the pathologic features. Individual studies were mostly hospital-based, which could also potentially prevent the inference of our results to the general population. Second, the age, size, number and location of IPH as well as the size of ulceration and thrombosis could influence the strength of association. Nevertheless, we could not draw a valid estimate because few studies provided specific data. Finally, our study was based on a qualitative evaluation. A number of quantitative reports have surged in the past decade. ${ }^{\left[{ }^{[0,46,65]}\right.}$ Similarly, an estimator was not permitted to be made mainly because of disparate methods in quantifying and insufficient details regarding these features.

\section{Acknowledgments}

This work was supported by the Beijing Municipal Science and Technology Commission, BMSTC (D0905002040231 and D0905004040131)

\section{References}

1. Barnett HJ, Taylor DW, Eliasziw M, Fox AJ, Ferguson GG, Haynes $\mathrm{RB}$, et al. Benefit of carotid endarterectomy in patients with symptomatic moderate or severe stenosis. North American Symptomatic Carotid Endarterectomy Trial Collaborators. N Engl J Med 1998;339:1415-25.

2. Randomized trial of endarterectomy for recently symptomatic carotid stenosis: Final results of the MRC European Carotid Surgery Trial (ECST). Lancet 1998;351:1379-87.

Halliday A, Mansfield A, Marro J, Peto C, Peto R, Potter J, et al. Prevention of disabling and fatal strokes by successful carotid endarterectomy in patients without recent neurological symptoms: randomised controlled trial. Lancet 2004;363:1491-502.

4. Golledge J, Greenhalgh RM, Davies AH. The symptomatic carotid plaque. Stroke 2000;31:774-81.

Inzitari D, Eliasziw M, Gates P, Sharpe BL, Chan RK, Meldrum HE, et al. The causes and risk of stroke in patients with asymptomatic internal-carotid-artery stenosis. North American Symptomatic Carotid Endarterectomy Trial Collaborators. N Engl J Med 2000;342:1693-700.

6. Droste DW, Karl M, Bohle RM, Kaps M. Comparison of ultrasonic and histopathological features of carotid artery stenosis. Neurol Res $1997 ; 19: 380-4$

7. Beletsky VY, Kelley RE, Fowler M, Phifer T. Ultrasound densitometric analysis of carotid plaque composition. Pathoanatomic correlation. Stroke 1996;27:2173-7.

8. Takaya N, Yuan C, Chu B, Saam T, Underhill H, Cai J, et al. Association between carotid plaque characteristics and subsequent ischemic cerebrovascular events: A prospective assessment with MRI-initial results. Stroke 2006;37:818-23

9. AbuRahma AF, Kyer PD $3^{\text {rd }}$, Robinson PA, Hannay RS. The correlation of ultrasonic carotid plaque morphology and carotid plaque hemorrhage: Clinical implications. Surgery 1998;124:721-8.

10. Sitzer M, Muller W, Rademacher J, Siebler M, Hort W, Kniemeyer HW, et al. Color-flow Doppler-assisted duplex imaging fails to detect ulceration in high-grade internal carotid artery stenosis. J Vasc Surg 1996;23:461-5.

11. Lammie GA, Wardlaw J, Allan P, Ruckley CV, Peek R, Signorini DF. What pathological components indicate carotid atheroma activity and can these be identified reliably using ultrasound? Eur J Ultrasound 2000;11:77-86

12. Chu B, Kampschulte A, Ferguson MS, Kerwin WS, Yarnykh VL, O'Brien KD, et al. Hemorrhage in the atherosclerotic carotid plaque: A high-resolution MRI study. Stroke 2004;35:1079-84.

13. Jander S, Sitzer M, Schumann R, Schroeter M, Siebler M, Steinmetz $\mathrm{H}$, et al. Inflammation in high-grade carotid stenosis: A possible role for macrophages and $\mathrm{T}$ cells in plaque destabilization. Stroke $1998 ; 29: 1625-30$. 
14. Hunt JL, Fairman R, Mitchell ME, Carpenter JP, Golden M, Khalapyan $\mathrm{T}$, et al. Bone formation in carotid plaques: A clinicopathological study. Stroke 2002;33:1214-9.

15. Milei J, Parodi JC, Alonso GF, Barone A, Grana D, Matturri L. Carotid rupture and intraplaque hemorrhage: Immunophenotype and role of cells involved. Am Heart J 1998;136:1096-105.

16. Carr SC, Farb A, Pearce WH, Virmani R, Yao JS. Activated inflammatory cells are associated with plaque rupture in carotid artery stenosis. Surgery 1997;122:757-64.

17. Chang JB, Stein TA. Late stroke in patients after carotid endarterectomy. J Surg Res 1997;73:155-9.

18. Lovett JK, Gallagher PJ, Hands LJ, Walton J, Rothwell PM Histological correlates of carotid plaque surface morphology on lumen contrast imaging. Circulation 2004;110:2190-7.

19. Mauriello A, Sangiorgi G, Palmieri G, Virmani R, Holmes DR Jr, Schwartz RS, et al. Hyperfibrinogenemia is associated with specific histocytological composition and complications of atherosclerotic carotid plaques in patients affected by transient ischemic attacks. Circulation 2000;101:744-50.

20. Altaf N, Daniels L, Morgan PS, Lowe J, Gladman J, MacSweeney ST, et al. Cerebral white matter hyperintense lesions are associated with unstable carotid plaques. Eur J Vase Endovase Surg 2006;31:8-13.

21. Endo S, Hirashima Y, Kurimoto M, Kuwayama N, Nishijima M, Takaku A. Acute pathologic features with angiographic correlates of the nearly or completely occluded lesions of the cervical internal carotid artery. Surg Neurol 1996;46:222-8.

22. Redgrave JN, Lovett JK, Gallagher PJ, Rothwell PM. Histological assessment of 526 symptomatic carotid plaques in relation to the nature and timing of ischemic symptoms: The Oxford plaque study. Circulation 2006;113:2320-8.

23. Orlandi G, Parenti G, Bertolucei A, Puglioli M, Collavoli P, Murri L. Carotid plaque features on angiography and asymptomatic cerebral microembolism. Acta Neurol Scand 1997;96:183-6.

24. Lovett JK, Howard SC, Rothwell PM. Pulse pressure is independently associated with carotid plaque ulceration. J Hypertens 2003;21:1669-76.

25. Gonzalez A, Gonzalez-Mareos JR, Martinez E, Boza F, Cayuela A, Mayol A, et al. Safety and security of carotid artery stenting for severe stenosis with contralateral occlusion. Cerebrovase Dis $2005 ; 20: 123-8$

26. Carr S, Farb A, Pearce WH, Virmani R, Yao JS. Atherosclerotic plaque rupture in symptomatic carotid artery stenosis. J Vasc Surg $1996 ; 23: 755-66$.

27. Bassiouny HS, Sakaguchi Y, Mikucki SA, McKinsey JF, Piano G, Gewertz BL, et al. Juxtalumenal location of plaque necrosis and neoformation in symptomatic carotid stenosis. J Vase Surg 1997;26:585-94.

28. Park AE, McCarthy WJ, Pearce WH, Matsumura JS, Yao JS. Carotid plaque morphology correlates with presenting symptomatology. J Vase Surg 1998;27:872-9.

29. McCarthy MJ, Loftus IM, Thompson MM, Jones L, London NJ, Bell PR, et al. Angiogenesis and the atherosclerotic carotid plaque: An association between symptomatology and plaque morphology. J Vase Surg 1999;30:261-8.

30. Montauban van Swijndregt AD, Elbers HR, Moll FL, de Letter J, Ackerstaff RG. Cerebral ischemic disease and morphometric analyses of carotid plaques. Ann Vase Surg 1999;13:468-74.

31. Ballotta E, Da Giau G, Renon L. Carotid plaque gross morphology and clinical presentation: A prospective study of 457 carotid artery specimens. J Surg Res 2000;89:78-84.

32. Kim DI, Lee SJ, Lee BB, Kim YI, Chung CS, Seo DW, et al. The relationship between the angiographic findings and the clinical features of carotid artery plaque. Surg Today 2000;30:37-42.

33. Tegos TJ, Sohail M, Sabetai MM, Robless P, Akbar N, Pare G, et al. Echomorphologic and histopathologic characteristics of unstable carotid plaques. AJNR Am J Neuroradiol 2000;21:1937-44.

34. Mallat Z, Corbaz A, Scoazec A, Besnard S, Leseche G, Chvatchko $\mathrm{Y}$, et al. Expression of interleukin-18 in human atherosclerotic plaques and relation to plaque instability. Circulation 2001;104:1598-603.
35. Stork JL, Kimura K, Levi CR, Chambers BR, Abbott AL, Donnan GA. Source of microembolic signals in patients with high-grade carotid stenosis. Stroke 2002;33:2014-8.

36. Milei J, Parodi JC, Ferreira M, Barrone A, Grana DR, Matturri L. Atherosclerotic plaque rupture and intraplaque hemorrhage do not correlate with symptoms in carotid artery stenosis. J Vase Surg 2003;38:1241-7.

37. Spagnoli LG, Mauriello A, Sangiorgi G, Fratoni S, Bonanno E, Schwartz RS, et al. Extracranial thrombotically active carotid plaque as a risk factor for ischemic stroke. JAMA 2004;292:1845-52.

38. Fisher M, Paganini-Hill A, Martin A, Cosgrove M, Toole JF, Barnett HJ, et al. Carotid plaque pathology: Thrombosis, ulceration and stroke pathogenesis. Stroke 2005;36:253-7.

39. Tziakas DN, Lazarides MK, Tentes IK, Georgiadis GS, Eleftheriadou E, Chalikias GK, et al. Gelatinases [matrix metalloproteinase-2 (MMP-2) and MMP-9] induce carotid plaque instability but their systemic levels are not predictive of local events. Ann Vase Surg 2005;19:529-33.

40. Krupinski J, Turu MM, Martinez-Gonzalez J, Carvajal A, JuanBabot JO, Iborra E, et al. Endogenous expression of C-reactive protein is increased in active (ulcerated noncomplicated) human carotid artery plaques. Stroke 2006;37:1200-4.

41. Turu MM, Krupinski J, Catena E, Rosell A, Montaner J, Rubio F, et al. Intraplaque MMP-8 levels are increased in asymptomatic patients with carotid plaque progression on ultrasound. Atherosclerosis 2006;187:161-9.

42. Lovett JK, Redgrave JN, Rothwell PM. A critical appraisal of the performance, reporting and interpretation of studies comparing carotid plaque imaging with histology. Stroke 2005;36:1091-7.

43. Hertzer NR, Beven EG, Benjamin SP. Ultramicroscopic ulceration and thrombi of the carotid bifurcation. Arch Surg 1977;112:1394402

44. Moore WS, Boren C, Malone JM, Roon AJ, Eisenberg R, Goldstone $J$, et al. Natural history of nonstenotic, asymptomatic ulcerative lesions of the carotid artery. Arch Surg 1978;113:1352-9.

45. Sterpetti AV, Hunter WJ, Schultz RD. Importance of ucleration of carotid plaque in determining symptoms of cerebral ischemia. J Cardiovase Surg 1991;32:154-8.

46. Bassiouny HS, Davis H, Massawa N, Gewertz BL, Glagov S, Zarins CK. Critical carotid stenoses: Morphologic and chemical similarity between symptomatic and asymptomatic plaques. J Vase Surg $1989 ; 9: 202-12$

47. Imparato AM, Riles TS, Mintzer R, Baumann FG. The importance of hemorrhage in the relationship between gross morphologic characteristics and cerebral symptoms in 376 carotid artery plaques. Ann Surg 1983;197:195-203.

48. O'Leary DH, Holen J, Ricotta JJ, Roe S, Schenk EA. Carotid bifurcation disease: Prediction of ulceration with B-mode US. Radiology 1987;162:523-5.

49. Comerota AJ, Katz ML, White JV, Grosh JD. The preoperative diagnosis of the ulcerated carotid atheroma. J Vase Surg 1990;11:505-10

50. Fisher M, Martin A, Cosgrove M, Norris JW. The NASCET-ACAS plaque project. North American Symptomatic Carotid Endarterectomy Trial. Asymptomatic Carotid Atherosclerosis Study. Stroke 1993;24:I24-32.

51. Sitzer M, Muller W, Siebler M, Hort W, Kniemeyer HW, Jancke L, et al. Plaque ulceration and lumen thrombus are the main sources of cerebral microemboli in high-grade internal carotid artery stenosis. Stroke 1995;26:1231-3.

52. Harrison MJ, Marshall J. The finding of thrombus at carotid endarterectomy and its relationship to the timing of surgery. $\mathrm{Br} \mathrm{J}$ Surg 1977;64:511-2

53. Imparato AM, Riles TS, Gorstein F. The carotid bifurcation plaque: Pathologic findings associated with cerebral ischemia. Stroke 1979;10:238-45.

54. Lusby RJ, Ferrel LD, Ehrenfeld WK, Stoney J, Wylie EJ. Carotid plaque hemorrhage: Its role in the production of cerebral ischemia. Arch Surg 1982;117:1479-88.

55. Ammar AD, Wilson RL, Travers H, Lin JJ, Farha SJ, Chang FC. 
Intraplaque hemorrhage: Its significance in cerebrovascular disease. Am J Surg 1984;148:840-3.

56. Lennihan L, Kupsky WJ, Mohr JP, Hauser WA, Correll JW, Quest DO. Lack of association between carotid plaque hematoma and ischemic cerebral symptoms. Stroke 1987;18:879-81.

57. Bornstein NM, Krajewski A, Lewis AJ, Norris JW. Clinical significance of carotid plaque hemorrhage. Arch Neurol $1990 ; 47: 958-9$

58. Persson AV, Robichaux WT, Silverman M. The natural history of carotid plaque development. Arch Surg 1983;118:1048-52.

59. Saam T, Ferguson MS, Yarnykh VL, Takaya N, Xu D, Polissar NL, et al. Quantitative evaluation of carotid plaque composition by in vivo MRI. Arterioseler Thromb Vase Biol 2005;25:234-9.

60. Zhao XQ, Yuan C, Hatsukami TS, Frechette EH, Kang XJ, Maravilla KR, et al. Effects of prolonged intensive lipid-lowering therapy on the characteristics of carotid atherosclerotic plaques in vivo by MRI: A case-control study. Arterioscler Thromb Vase Biol 2001;21:1623-9.

61. Fujii K, Kobayashi Y, Mintz GS, Takebayashi H, Dangas G, Moussa I, et al. Intravascular ultrasound assessment of ulcerated ruptured plaques: A comparison of culprit and nonculprit lesions of patients with acute coronary syndromes and lesions in patients without acute coronary syndromes. Circulation 2003;108:2473-8.

62. Verheye S, De Meyer GR, Van Langenhove G, Knaapen MW, Kockx MM. In vivo temperature heterogeneity of atherosclerotic plaques is determined by plaque composition. Circulation 2002;105:1596-601.

63. Manca G, Parenti G, Bellina R, Boni G, Grosso M, Bernini W, et $a l .{ }^{111}$ In platelet scintigraphy for the noninvasive detection of carotid plaque thrombosis. Stroke 2001;32:719-27.

64. Takaya N, Yuan C, Chu B, Saam T, Polissar NL, Jarvik GP, et al. Presence of Intra-plaque hemorrhage stimulates progression of carotid atherosclerotic plaques: A high-resolution magnetic resonance imaging study. Circulation 2005;111:2768-75.

65. Hatsukami TS, Ferguson MS, Beach KW, Gordon D, Detmer P, Burns D, et al. Carotid plaque morphology and clinical events. Stroke 1997;28:95-100.

\section{Accepted on 09-02-2007}

Source of Support: Beijing Municipal Science and Technology Commission (D0905002040231 and D0905004040131), China, Conflict of Interest: None declared. 